\section{Polymer science}

Macromolecules. Vol. 1: Structure and Properties. Pp. 532. Vol. 2: Synthesis and Materials. By Hans-Georg Elias. Pp. 131. (Wiley: London; Plenum: New York, 1977.) $£ 24$; $\$ 42.50$ each volume.

IN his preface, the author describes thesc two volumes as a textbook, treating "the whole field of macromolecular science, from its chemistry and physics to its applications, in a not too elementary manner." To attempt this is a stupendous undertaking for a single author, but it can be said at once that the text amply justifies the claim. The original version (1971) was in German and the present text is a translation from a 1975 revised German edition-but shows no internal evidence of not having been written in English from the start.

The method adopted is that of straightforward exposition; where differing viewpoints might be held, the author usually takes a clear line, no doubt with the aim of avoiding confusion for the student. The area to be covered is vast, and within the scope of 1,100 pages most topics can receive no more than outline treatment. To enable the student to supplement this, a reading list of books and review articles is provided for each section, but there are no references to the original literature (except for historical introduction). The opportunity has evidently been taken in revision and again in translation to add recent titles to the original reading lists.

The contents of the two volumes can be described roughly as physics and chemistry, respectively; and although the work is planned as a whole, the two parts could each stand alonc. Volume 1 deals with the theoretical and experimental basis of our knowledge of polymer structure, and physical properties. It is divided into three parts: structure, solution properties, and solid-state properties. Little is assumed in the way of background knowledge: chapter 5 opens with an account of X-ray scattering; and chapter 9.5 with a presentation of the basic principles of light scattering. Experimental methods are outlined, and although equipment is not described in detail, key features are frequently pointed out. Although this volume is largely concerned with principles, it is sufficiently wide-ranging to include reference to such practical matters as adhesives and glues, and the testing of insulators for resistance to tracking.

Volume 2 divides into two roughly equal parts dealing, respectively, with principles of polymerisation and individual polymers. Following an introducttory chapter on general principles, the first part deals successively with polycondensations; ionic, insertion and radical reactions, copolymerisation; and finally with reactions of macromolecules (including aging). This is a wide-sweeping survey at a very well chosen level.

The last section of the book is entitled "Polymers" and is divided into nine chapters, of which the first four deal broadly with synthetic organic polymers classified according to their main chains: carbon, carbon-oxygen, carbon-sulphur, carbon-nitrogen. The chapters are further broken down by polymer type into 25 sections, many of them further subdivided. The general method of treatment for each polymer includes monomer synthesis, polymerisation methods and mechanisms, polymer properties and reactions; all done very competently and succinctly. Final chapters extend the scope to biopolymers and inorganic chains, and serve at least to remind the student of the wide ramifications of macromolecules in nature.

Nothing could be easier for the reviewer of a work of this kind than to select a field in which he is personally expert and

\section{Volcanic leitmotive}

Carbonatite-Nephelinite Volcanism. By MichaeI J. Le Bas. Pp. 347. (Wiley: London, New York and Toronto, 1977.) £22; $\$ 44$.

THERE is a long standing joke that one can doze off during one of Wagner's Ring of the Nibelungen operas, only to wake up ten minutes later to find the same singer standing on the same spot singing the same song. One gets the same impression from Le Bas' book. No matter where one dips into it, there is a certain sameness about the text. Tortuous rock names like uncomphagrite, turjaite, melteigite, ijolite and urtite keep cropping up in the prose like Wagnerian leitmotive. To appreciate the Ring, one has to be able to recognise the leitmotive. The same is true of this book: without a firm grasp of the convoluted terminology of hyper-alkalic volcanism, one is lost.

The first sentence of the first paragraph of the text starts: "The classic igneous intrusions of Fen (Brogger, 1921; Sacther, 1957) and Alno (Eckermann, 1948) in Scandinavia, of Magnet Cove, Arkansas (Erickson and Biade, 1963), of Iron Hill, Powderhorn, Colorado...". This bleak style is relentlessly preserved throughout the 24 chapters of the book. Nineteen of these are detailed descriptions of individual areas or volcanoes in East Africa written by Le Bas and his colleagues who worked in the area to point out shortcomings and possible errors of judgement. Inevitably, when an author undertakes to review such a vast field he will succeed better with some areas than others. What is more pertinent to ask is (a) whether the work succeeds in its declared aim, and (b) what other needs it might serve. On the first of these counts, there is no doubt that any student who works systematically through this text will acquire a broad knowledge and understanding of polymer science and its applications. Spread over the three years of a Ph.D. course, it would provide a superb accompaniment to the experimental study of a limited topic. For the reviewer, its role will be that of an admirable first source of information, providing a coherently argued introduction and a guide to further reading. On both counts, it is a notable addition to polymer literature.

Geoffrey Gee

Geoffrey Gee is Professor of Chemistry at the University of Manchester, UK.

from 1963 to 1969. Many of these chapters are based on the distilled and condensed Ph.D. theses of research students.

Of most interest to this reviewer was the third chapter, in which Le Bas unravels the nomenclature of the rock suites $\cdots$ this is essential reading and should come before chapter 1 -and the last two, which cover magmatic and metasomatic processes and the petrogenesis of the carbonatite nephelinite suite. There are two appendices, containing geochronological and major element geochemical data; there are few trace element data.

Le Bas has produced a thoroughly scholarly work summarising many years of work by him and his colleagues in East Africa, and one which is unequivocally aimed at a specialised readership. The descriptive chapters will undoubtedly provide a valuable source of information to workers studying alkalic volcanism in East Africa and it is clearly useful to have all this data published under one cover. It is a pity, however, that Le Bas did not broaden his scope slightly. There must be many potential readers, not directly involved in the field, who would be glad of an up-to-date and intelligible review of the fascinating petrological problems posed by the carbonatite-nephelinite suites. Only a small proportion of this book is likely to interest them.

Peter Francis

Peter Francis is Lecturer in the Department of Earth Sciences at the Open University, Milton Keynes, UK. 